\title{
Activation of the TLR4/MyD88 signaling pathway contributes to the development of human hepatocellular carcinoma via upregulation of IL-23 and IL-17A
}

\author{
YUMING KANG ${ }^{1}$, GUOAI SU ${ }^{2}$, JIANMIN $\mathrm{SUN}^{3}$ and YANLI ZHANG ${ }^{3}$ \\ ${ }^{1}$ Department of Hepatobiliary Surgery, The General Hospital of Ningxia Medical University, Yinchuan, Ningxia 750004; \\ ${ }^{2}$ Department of Internal Medicine, The Army General Hospital of The Chinese People's Liberation Army, \\ Beijing 100700; ${ }^{3}$ Department of Pathogen Biology and Immunology, School of Basic Medical Sciences, \\ Ningxia Medical University, Yinchuan, Ningxia 750004, P.R. China
}

Received February 20, 2017; Accepted November 10, 2017

DOI: $10.3892 / \mathrm{ol} .2018 .8586$

\begin{abstract}
Toll-like receptor 4 (TLR4) and the interleukin (IL)-23/IL-17A axis serve an important role in tumor immunology. In the present study, the activation of the TLR4/myeloid differentiation primary response 88 (MyD88)-mediated signal transduction pathway in human hepatocellular carcinoma (HCC) cells was examined using immunohistochemistry, and the association between TLR4 expression and the IL-23/IL-17A axis was detected by ELISA, reverse transcription-quantitative polymerase chain reaction and western blot analysis in order to determine whether TLR4 and IL-23/IL-17A serve a role in HCC. It was observed that TLR4 expression was upregulated in HCC tissues compared with that in adjacent normal tissues. In addition, the TLR4 expression level was correlated with the degree of tumor differentiation and TNM stage. The expression levels of IL-17A and IL-23, which are key mediators of inflammation that contribute to carcinogenesis, are correlated with TLR4 expression in HCC. Cell line studies further revealed that activation of TLR4/MyD88 upregulated the expression of IL-17A and IL-23 at the mRNA and protein levels. Furthermore, activation of TLR4/MyD88 enhanced the expression of TLR4. IL-17A and IL-23 expression levels in HCC also appeared to be correlated with the TNM stage and tumor metastasis. In conclusion, the current results suggested that the TLR4/MyD88 signaling pathway is involved in HCC cell proliferation and metastasis via regulation of the IL-23/IL-17A axis; thus, the TLR4/IL-23/IL-17A pathway may represent a novel therapeutic target in $\mathrm{HCC}$.
\end{abstract}

Correspondence to: Professor Yanli Zhang, Department of Pathogen Biology and Immunology, School of Basic Medical Sciences, Ningxia Medical University, 1160 Shengli Street, Yinchuan, Ningxia 750004, P.R. China

E-mail: zhangyl@nxmu.edu.cn

Key words: hepatocellular carcinoma, interleukin-23, interleukin-17, Toll-like receptor 4

\section{Introduction}

Human hepatocellular carcinoma (HCC) is the third most common cause of mortality due to cancer and the fifth most common malignancy worldwide, with a particularly high incidence observed in Africa and Asia (1). Liver carcinogenesis is generally considered to be associated with inflammation caused by environmental factors, including hepatitis B and C viral infections, which are the major risk factors of $\operatorname{HCC}(2,3)$.

Toll-like receptor 4 (TLR4) is a well-studied member of the TLR protein family. Lipopolysaccharide (LPS) released from bacteria can bind to TLR4, leading to the activation of TLR4 and myeloid differentiation primary response 88 (MyD88). Signaling via TLR4/MyD88 initiates the activation of nuclear factor- $\kappa \mathrm{B}(\mathrm{NF}-\kappa \mathrm{B})$ and a subsequent expression of pro-inflammatory genes that trigger the host inflammatory response to infection $(4,5)$. TLR4 is overexpressed in various types of human cancer, including breast cancer, melanoma, colon cancer, ovary cancer and prostate cancer (6-10). TLR4 expression and activation of the TLR4/MyD88-mediated signaling pathways promote carcinogenesis and metastasis $(11,12)$. Furthermore, it has been demonstrated that TLR4 contributes to the growth and migration of hepatocellular tumors $(13,14)$.

An inflammatory microenvironment is a hallmark of tumor-associated inflammation (15). Chronic inflammation induces DNA damage and oncogenic mutations, causing cancer formation and progression (16-18). Interleukin (IL)-23, a member of the IL-12 family, is a heterodimeric pro-inflammatory cytokine that is mainly produced by inflammatory myeloid cells. IL-23 stimulates T cells to differentiate into T helper 17 (Th17) cells in the presence of IL-6 and transforming growth factor- $\beta$ (19). Th17 cells are a population of $\mathrm{T}$ helper lymphocytes, and include the subtypes of IL-17A, IL-17B, IL-17C, IL-17D, IL-17E/IL-25 and IL-17F. These cells are able to produce another pro-inflammatory cytokine, IL-17 (20). IL-17 recruits neutrophils, enhances dendritic cell maturation and stimulates macrophages to produce IL-1 $\beta$ and tumor necrosis factor (TNF)- $\alpha$, which then induce and mediate pro-inflammatory responses (21). An increasing number of 
studies demonstrated that the IL-23/IL-17A axis contributes to cancer growth and metastasis. Furthermore, this axis can reduce the infiltration of $\mathrm{CD} 8^{+}$cells in tumors and enhance the immunosuppressive activity of regulatory $\mathrm{T}$ cells $(22,23)$.

In the present study, the expression of TLR4 in HCC tissues and its correlation with the clinical features of HCC was analyzed. In addition, the correlation between TLR4 expression and the IL-23/IL-17A axis in HCC were examined in order to determine whether IL-23 and IL-17A serve a role in its carcinogenesis.

\section{Materials and methods}

Chemicals. Primers were synthesized by SBS Genetech Co., Ltd. (Beijing, China). The primary antibodies against TLR4 (dilution 1:400; cat. no. ab13556), IL-23 (dilution 1:400; cat. no. ab45420), IL-17A (dilution 1:200; cat. no. ab136668) and $\beta$-actin (dilution 1:1,000; cat. no. ab8227) were all purchased from Abcam (Cambridge, UK). ELISA kits for the detection of IL-23 (cat. no. F0153) and IL-17A (cat. no. F01451) levels were provided by Westang Biological Technology Co., Ltd. (Shanghai, China). LPS was obtained from Sigma-Aldrich (Merck KGaA, Darmstadt, Germany), while the MyD88 inhibitor ST2825 was from MedChemExpress (Monmouth Junction, NJ, USA). TRIzol ${ }^{\circledR}$ reagent, fetal bovine serum (FBS), Dulbecco's modified Eagle's medium (DMEM), and the SYBR-Green PCR Master Mix, bicinchoninic acid (BCA) and enhanced chemiluminescence (ECL) kits were purchased from Thermo Fisher Scientific, Inc. (Waltham, MA, USA). The reverse transcription (RT) kit was supplied by Promega Corporation (Madison, WI, USA).

Cell culture. Human liver cancer HepG2 cells were obtained from the Type Culture Collection of the Chinese Academy of Sciences (Shanghai, China). The cells were cultured in DMEM supplemented with $10 \%$ FBS, penicillin $(100 \mathrm{U} / \mathrm{ml})$ and streptomycin $(100 \mathrm{~g} / \mathrm{ml})$ in a humidified atmosphere containing $5 \% \mathrm{CO}_{2}$ at $37^{\circ} \mathrm{C}$.

Human tissues. The application of clinical samples was reviewed and approved by the Ethics Committee of Ningxia Medical University (Yinchuan, China), and patients provided written informed consent. Based on the National Standard for Diagnosis and Treatment of Primary Liver Cancer (2011 edition) guidelines (24), 45 paraffin-embedded tissue samples of primary HCC from patients who had not received radiotherapy or chemotherapy prior to surgery were collected at the General Hospital of Ningxia Medical University between October 2012 and December 2014. The patients were graded on the basis of the tumor-node-metastasis (TNM) stage (25). There were 17 adjacent normal tissues also collected and served as the controls. All the samples were embedded in paraffin and stored at $4^{\circ} \mathrm{C}$ after sectioning.

Immunohistochemical assay. Tissue sections (thickness, $4 \mu \mathrm{m}$ ) were deparaffinized in xylene, soaked in alcohol and treated in antigen unmasking solution (Beijing Zhongshan Golden Bridge Biotechnology Co., Ltd., Beijing, China) in the microwave for $10 \mathrm{~min}$, followed by incubation in $3 \%$ hydrogen peroxide for $10 \mathrm{~min}$ to inactivate the endogenous
Table I. Sequences of primers used in quantitative polymerase chain reaction assay.

\begin{tabular}{ll}
\hline Genes & \multicolumn{1}{c}{ Primer sequence (5'-3') } \\
\hline TLR4 & F: GCAGTTTCTGAGCAGTCGTG \\
& R: CTGTCCTCCCACTCCAGGTA \\
IL-23 & F: GCCTTCTCTGCTCCCTGATA \\
& R: GACTGAGGCTTGGAATCTGC \\
IL-17A & F: CGATCCACCTCACCTTGGAA \\
& R: TAGTCCACGTTCCCATCAGC \\
GAPDH & F: CAATGACCCCTTCATTGACC \\
& R: GACAAGCTTCCCGTTCTCAG
\end{tabular}

TLR4, Toll-like receptor 4; IL, interleukin; F, forward; R, reverse.

peroxidase. The sections were then incubated with antibodies against TLR4, IL-23, IL-17A and $\beta$-actin at $4^{\circ} \mathrm{C}$ overnight. Immunostaining was performed using the Histostain ${ }^{\mathrm{TM}}-$ Plus kit (cat.no. 859073; Thermo Fisher Scientific, Inc.) according to the manufacturer's instructions. Two independent researchers evaluated each stained section. Immunohistochemical staining was evaluated by the intensity and distribution of cytoplasmic staining. Staining intensity was graded as follows: 0 , no staining; 1 , weak staining; 2 , moderate staining; and 3 , strong staining. Staining distribution was based on the percentage of stained tumor cells: $0,0 \% ; 1,<25 \% ; 2,25-50 \% ; 3,51-75 \%$ and $4,>75 \%$ (26). The final staining scores were calculated as follows: Staining intensity $\mathrm{x}$ the percentage of stained tumor cells.

ELISA. Cells were seeded in 96-well plates at a density of $5 \times 10^{4}$ cells/well and cultured for $24 \mathrm{~h}$, followed by exposure to $1 \mathrm{mg} / \mathrm{l} \mathrm{LPS}$ for 12,24 or $36 \mathrm{~h}$ alone or pretreated with $40 \mu \mathrm{mol} / \mathrm{l} \mathrm{ST} 2825$ for $8 \mathrm{~h}$, prior to being treated with $1 \mathrm{mg} / 1$ LPS for 12, 24 or $36 \mathrm{~h}$. The control cells were cultured with DMEM. The supernatant was centrifuged at $12,000 \mathrm{x}$ g for 5 min at $4^{\circ} \mathrm{C}$ and the concentration of IL-23 and IL-17A in the culture medium was measured by an ELISA kit, according to the manufacturer's instructions. The absorbance was then detected spectrophotometrically at $450 \mathrm{~nm}$ using a microplate reader and plotted against a standard curve with standard levels expressed as $\mathrm{pg} / \mathrm{ml}$. Each sample was analyzed in triplicate.

$R N A$ extraction and RT-quantitative polymerase chain reaction $(q P C R)$. HepG2 cells were treated with LPS (1 mg/l) for $24 \mathrm{~h}$, alone or followed by ST2825 $(40 \mu \mathrm{mol} / \mathrm{l})$ treatment for $8 \mathrm{~h}$. The control cells were cultured with DMEM. Total RNA was extracted from HepG2 cells by TRIzol reagent, and further purified using RNeasy Mini columns (cat no. 74104; Qiagen GmbH, Hilden, Germany). Complementary DNA (cDNA) was then synthesized using a high-capacity cDNA reverse transcription kit. Subsequently, qPCR assays were performed in triplicate using SYBR ${ }^{\circledR}$ Green PCR Master Mix with the following thermal cycling conditions: $95^{\circ} \mathrm{C}$ for $10 \mathrm{~min}$, 40 cycles of denaturation at $95^{\circ} \mathrm{C}$ for $15 \mathrm{sec}$, annealing at $60^{\circ} \mathrm{C}$ for $30 \mathrm{sec}$ and extension at $72^{\circ} \mathrm{C}$ for $30 \mathrm{sec}$. The sequences of 

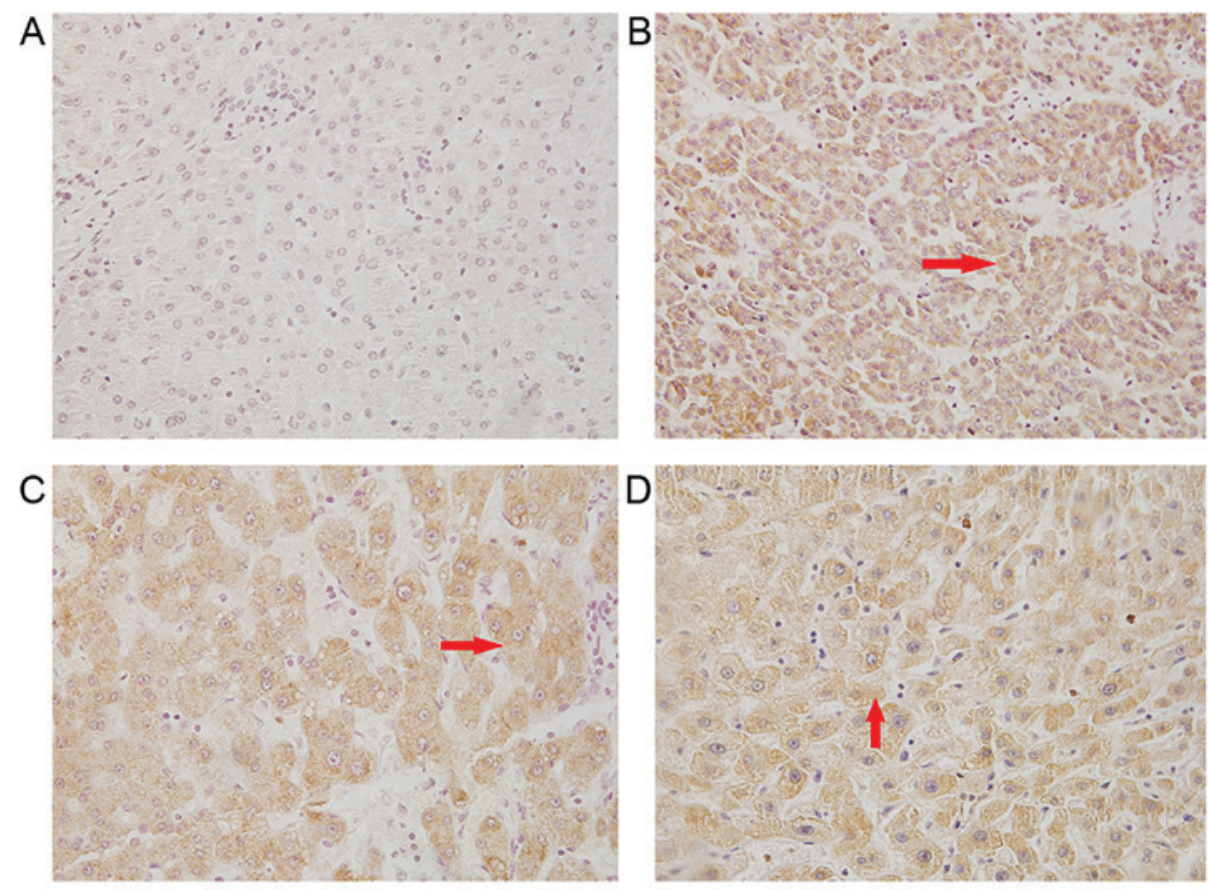

Figure 1. Immunohistochemical staining of TLR4, IL-23 and IL-17A in HCC tissues was observed using a microscope (x400 magnification). The arrow indicates the positive yellow and brown staining for these proteins. (A) Adjacent non-cancerous tissues. (B) TLR4, (C) IL-23 and (D) IL-17A expression in HCC tissue. TLR4, Toll-like receptor 4; IL, interleukin; HCC, hepatocellular carcinoma.

primers used in the qPCR assay are listed in Table I. The relative mRNA expression of HepG2 cells was calculated using the $2^{-\Delta \Delta \mathrm{Cq}}$ method (27), and normalized using GAPDH as the reference gene.

Western blot analysis. HepG2 cells were treated with the $40 \mu \mathrm{mol} / 1 \mathrm{ST} 2825$ and $1 \mathrm{mg} / \mathrm{l} \mathrm{LPS}$ for $24 \mathrm{~h}$. The control cells were cultured with DMEM. Next, cells were lysed in a radioimmunoprecipitation assay buffer containing 1\% NP-40, $150 \mathrm{mM} \mathrm{NaCl}, 50 \mathrm{mM}$ Tris- $\mathrm{HCl}, 50 \mathrm{mM} \mathrm{NaF}$ and $1 \mathrm{mM}$ $\mathrm{Na}_{3} \mathrm{VO}_{4}$. The protein concentration in the cell lysate was determined using a BCA Protein Assay kit. A total of $40 \mu \mathrm{g}$ protein was then separated via $20 \%$ SDS-PAGE, followed by transfer to a nitrocellulose membrane. The membranes were blocked with 5\% milk in Tris-buffered saline/Tween-20 (TBST) buffer at $4^{\circ} \mathrm{C}$ overnight and probed with primary antibodies against TLR4, IL-23 or IL-17A, and $\beta$-actin was used as the internal control. Membranes were subsequently washed three times with TBST for $5 \mathrm{~min}$ each and incubated with a horseradish peroxidase-conjugated secondary antibody for $1 \mathrm{~h}$ at room temperature. Following washing five times with 1X TBST for 5 min each time, the membranes were developed with ECL detection reagents, and the signal intensity was quantified by ImageJ (version 1.45s; National Institutes of Health, Bethesda, MD, USA).

Statistical analysis. All statistical analyses were performed with SPSS version 17.0 software (SPSS, Inc., Chicago, IL, USA). Quantitative variables are presented as the mean \pm standard deviation, and were analyzed with the Student's t-test, one-way analysis of variance, $\chi^{2}$ test or Pearson's correlation coefficient. $\mathrm{P}<0.05$ was considered to indicate statistically significant differences.

\section{Results}

TLR4 expression is upregulated in HCC tissues. TLR4 is a receptor that serves an important role in inflammation (28). The expression of TLR4 has been identified in several types of cancer, including liver, breast, colon, ovarian and prostate cancer, and melanoma, and its expression contributes to carcinogenesis $(6-10,13)$. In order to determine whether TLR4 is involved in the development of HCC, the expression of TLR4 in HCC tissues obtained from patients was assessed. Immunohistochemical staining with TLR4 antibody revealed that TLR4 was expressed in the cytoplasm and cell surface of cancer cells in the tissue sections, as observed by yellow and brown staining (Fig. 1). The positive rate of TLR4 in HCC tissues was 77.8\% (35/45; Table II), while this rate was only $20 \%$ in adjacent noncancerous tissues, suggesting an upregulation of TLR4 expression in HCC.

TLR4 expression is correlated with HCC clinicopathological characteristics. To further examine whether TLR4 expression in HCC serves a role in the carcinogenesis, the correlation between TLR4 expression and the clinicopathological characteristics of HCC patients was analyzed. As shown in Table II, there was no significant correlation of TLR4 expression with the age, tumor size or tumor differentiation of patients ( $P>0.05)$. However, high expression of TLR4 was correlated with sex and a lower TNM stage $(\mathrm{P}<0.05$; Table II), suggesting that TLR4 expression may contribute to the development of HCC.

TLR4 expression is correlated with the expression levels of $I L-17 A$ and IL-23 in HCC. IL-17A and IL-23 are key mediators 


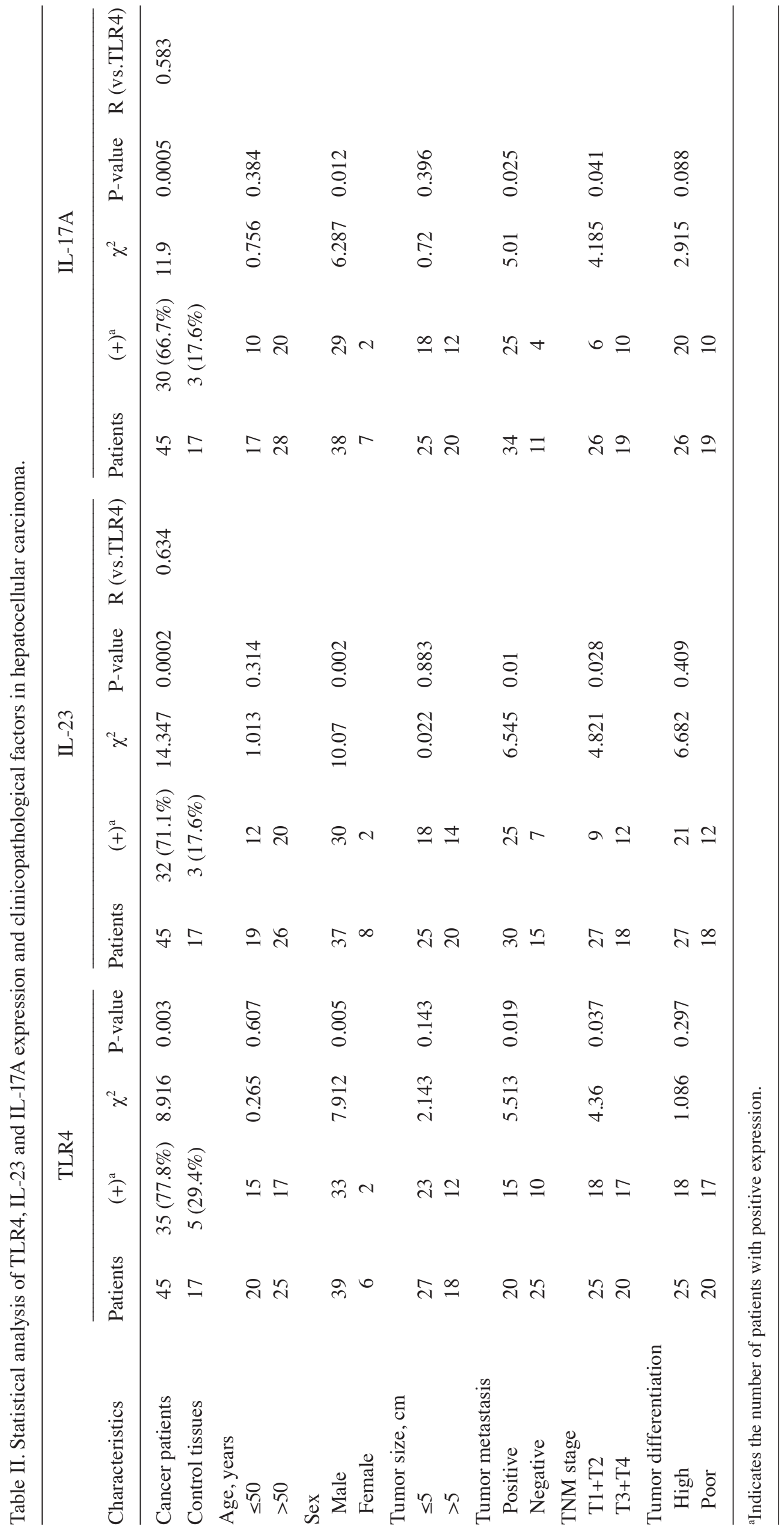



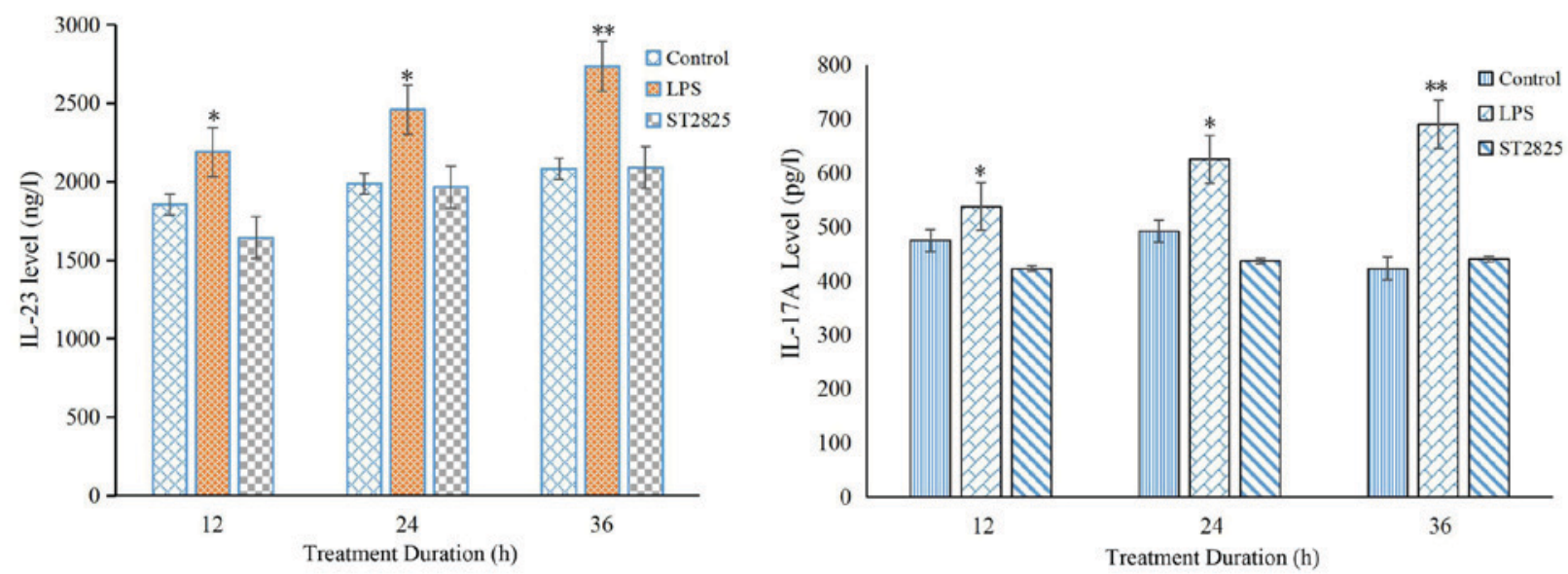

Figure 2. LPS promotes IL-23 and IL-17A expression in HepG2 cells, as measured by enzyme-linked immunosorbent assay. HepG2 cells were treated with $1 \mathrm{mg} / \mathrm{l} \mathrm{LPS} \mathrm{for} 12,24$ or $36 \mathrm{~h}$, or pretreated with $40 \mu \mathrm{mol} / 1$ ST2 825 for $8 \mathrm{~h}$, followed by treatment with $1 \mathrm{mg} / 1 \mathrm{LPS}$ for 12,24 or $36 \mathrm{~h}$. The concentration of IL-23 and IL-17A in the culture medium was quantified by measuring the absorbance at $450 \mathrm{~nm}$ with a microplate reader. Results are representative of three independent experiments. ${ }^{*} \mathrm{P}<0.05$ and ${ }^{* *} \mathrm{P}<0.01$ vs. control group. LPS, lipopolysaccharide; IL, interleukin.

A

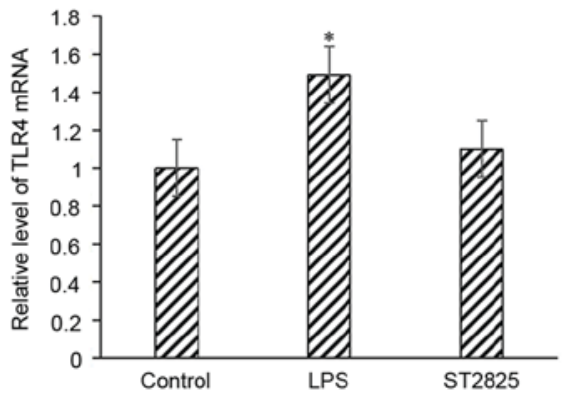

B

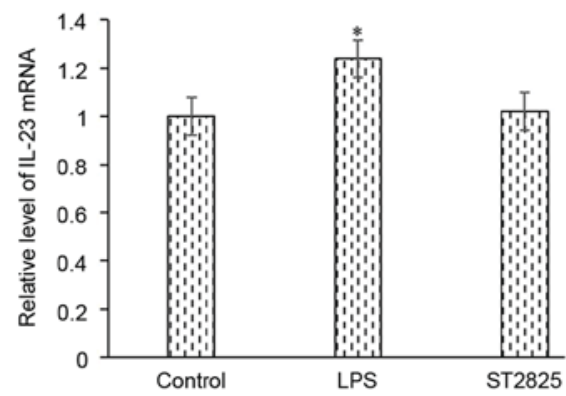

C

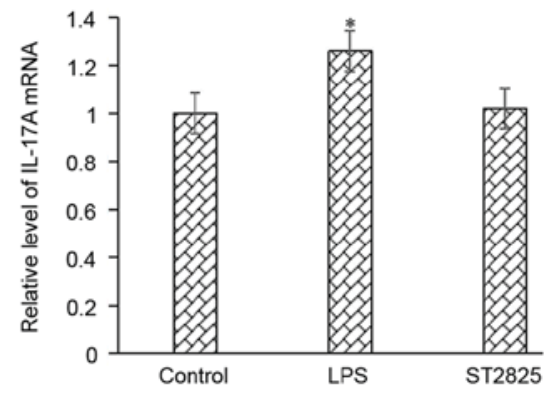

Figure 3. LPS promotes the mRNA expression levels of (A) TLR4, (B) IL-23 and (C) IL-17A, as determined by RT-qPCR. HepG2 cells were treated with $1 \mathrm{mg} / 1$ LPS for $24 \mathrm{~h}$, or were pretreated with $40 \mu \mathrm{mol} / 1 \mathrm{ST} 2825$ for $8 \mathrm{~h}$, followed by treatment with $1 \mathrm{mg} / 1 \mathrm{LPS}$ for $24 \mathrm{~h}$. "P<0.05 vs. control group. TLR4, Toll-like receptor 4; IL, interleukin; LPS, lipopolysaccharide.

of inflammation that contribute to carcinogenesis $(29,30)$. In order to establish whether TLR4 promotes carcinogenesis through IL-17A and IL-23 regulation, the correlation between TLR4 expression and the levels of IL-17A and IL-23 was examined. The results identified that the expression of TLR4 was associated with the levels of IL-17A ( $R=0.583)$ and IL-23 $(\mathrm{R}=0.634)$ in $\mathrm{HCC}$ (Table II), indicating a possible regulation effect between the expression of TLR4 and that of IL-17A and IL-23.

Expression levels of IL-23 and IL-17A are regulated by TLR4/MyD88 in HCC cells. TLR4 is a receptor expressed in all cell types in the liver, including hepatocytes cells, and is able to recognize LPS from the bacterial wall. Activation of TLR4 triggers an inflammatory response through MyD88-mediated activation of downstream signaling pathways $(4,5)$. As TLR4 expression was correlated with IL-23 and IL-17A expression in HCC tumors, as discussed earlier, the study further examined whether activation of the TLR4/MyD88 pathway regulates the expression levels of IL-23 and IL-17A proteins. As determined by western blot analysis, LPS induced the activation of TLR4, leading to enhanced expression of IL-23 and IL-17A in HCC cells. The expression of these interleukins was subsequently blocked by incubation with the MyD88 inhibitor, ST2825, and showed a time-dependent effect (Fig. 2). Analysis of IL-23 and IL-17A levels using an ELISA assay further confirmed this result, indicating that the expression levels of IL-23 and IL-17A were regulated by the TLR4/MyD88 signaling pathway in HCC cells (Fig. 2).

TLR4/MyD88 signaling pathway regulates the transcription of $I L-23$ and $I L-17 A$. Enhanced gene expression may be due to the upregulation of gene transcription. Using RT-qPCR, it was observed that LPS treatment of HepG2 cells resulted in enhanced transcription of IL-23 and IL-17A, while this upregulation of gene transcription was then blocked upon incubation with a MyD88 inhibitor (Fig. 3). These findings indicated that activation of the TLR4/MyD88 signaling pathway enhances the expression of IL-23 and IL-17A through the upregulation of gene transcription.

Activation of TLR4/MyD88 enhances TLR4 expression. The present study further examined whether activation of TLR4 regulates the expression of itself. RT-qPCR and western blot analyses revealed that stimulation of HepG2 cells with the TLR4-ligand LPS enhanced 
A

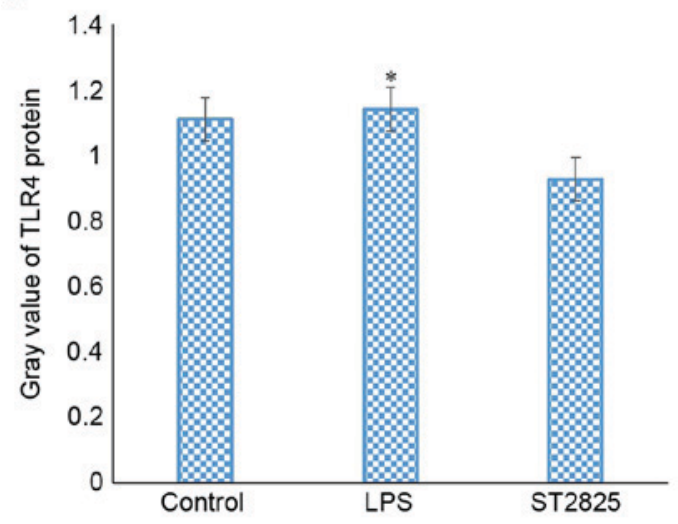

$\mathrm{C}$

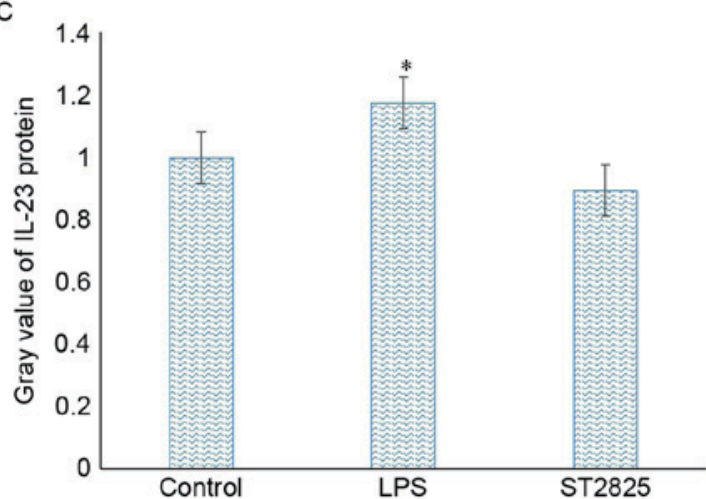

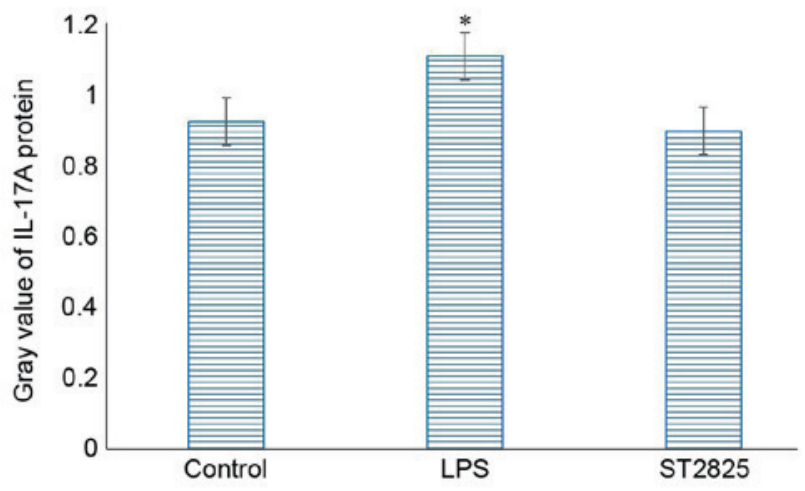

D

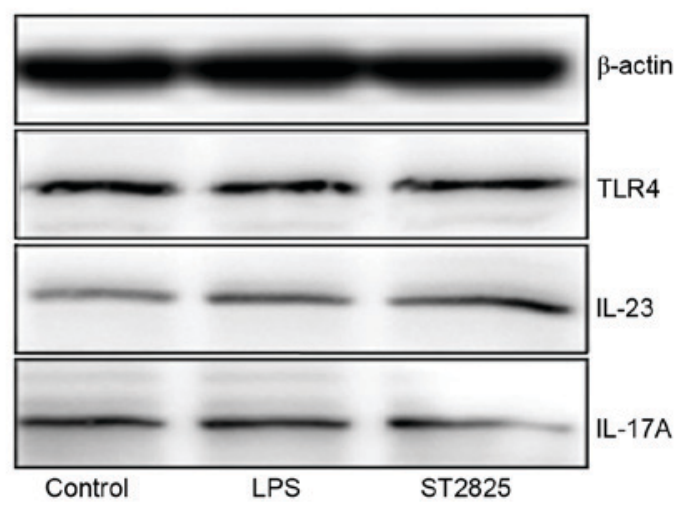

Figure 4. LPS promotes the protein expression levels of (A) TLR4, (B) IL-17A and (C) IL-23 as demonstrated by the quantified results. (D) Western blots of TLR4, IL-23 and IL-17A protein levels are also shown. HepG2 cells were treated with $1 \mathrm{mg} / 1 \mathrm{LPS}$ alone for $24 \mathrm{~h}$, or pretreated with $40 \mu \mathrm{mol} / \mathrm{l} \mathrm{ST} 2825$ for $8 \mathrm{~h}$, followed by treatment with $1 \mathrm{mg} / 1$ LPS for $24 \mathrm{~h}$. "P<0.05 vs. control group. TLR4, Toll-like receptor 4; IL, interleukin; LPS, lipopolysaccharide.

the expression levels of TLR4 mRNA and protein, whereas application of the MyD88 inhibitor blocked the upregulation of TLR4 expression induced by LPS. These results indicate a positive feedback loop of TLR4 activation and its expression (Fig. 4).

Expression levels of $I L-23$ and IL-17A are correlated with the HCC clinicopathological characteristics. Since the expression of TLR4 was correlated with the clinical features of HCC, and activation of TLR4 was observed to upregulate the expression levels of IL-23 and IL-17A, the current study further investigated whether the levels of IL-23 and IL-17A are also correlated with the clinical features of HCC. Analysis of the protein expression levels of IL-23 and IL-17A in HCC tumor tissues and adjacent normal tissues indicated that they were associated with sex, lymph node metastasis and the TNM stages of HCC $(\mathrm{P}<0.05)$. By contrast, no association was detected between these protein levels and the patient age, tumor size and tumor differentiation $(\mathrm{P}>0.05)$, as shown in Table II.

\section{Discussion}

Chronic inflammation is associated with the initiation, development and progression of carcinomas, and may contribute to cancer progression by activating angiogenesis and oncogenic signaling pathways (31). It is well known that HCC is a long-term consequence of chronic inflammatory liver diseases (32). In the present study, it was demonstrated that TLR4, IL-23 and IL-17A, which are involved in inflammation, were highly expressed in carcinoma tissues. In addition, the expression levels of TLR4, IL-23 and IL-17A were associated with lymph node metastasis and the TNM stages of HCC. It has previously been reported that the expression of TLR4 and MyD88 may be associated with breast cancer growth and distant metastases (6). In another study, Grivennikov et al (33) observed that IL-23 signaling promoted tumor growth and progression, as well as the development of a tumoral IL-17 response. The current study finding further supported the important role of the TLR4/MyD88 signaling pathway and IL-23/IL-17A in cancer.

The TLR4/MyD88 pathway mediates the activation of $\mathrm{NF}-\kappa \mathrm{B}$ and subsequent production of pro-inflammatory cytokines, including IL-1 $\beta$, IL- 6 and TNF- $\alpha$. These cytokines stimulate myeloid dendritic cells to secret IL-23, which promotes Th17 cell differentiation, proliferation and maintenance $(34,35)$. It has been reported that the IL-23/IL-17A axis promotes the formation of lung metastases through tumor-endothelial transmigration (36). In the present study, it was observed that the expression of TLR4 was associated with the expression levels of IL-17A $(\mathrm{R}=0.583)$ and IL-23 $(\mathrm{R}=0.634)$. To determine the possible role of the TLR4/MyD88 pathway and the IL-23/IL-17A axis in HCC, the study measured the TLR4, IL-23 and IL-17A expression 
levels in HepG2 cells stimulated with LPS using RT-qPCR and western blot analyses. The results revealed that LPS promoted the mRNA transcription and protein expression levels of TLR4, IL-23 and IL-17A in HepG2 cell lines, which were subsequently inhibited by incubation with the MyD88 inhibitor ST2825. Teng et al (37) previously reported that IL-23 was induced in response to stimulation by multiple TLR ligands, and this cytokine has been linked to autoimmune and inflammatory diseases. IL-23 consists of p19 and p40 units, while Brentano et al (38) further observed that the induction of p19 was TLR-dependent. In the present study, the data revealed that TLR4/MyD88 signaling regulated the expression levels of IL-23 and IL-17A in hepatocellular tumor cells.

In conclusion, the current study identified that the TLR4/MyD88 signaling pathway may be involved in hepatocellular carcinogenesis via upregulating the IL-23/IL-17A axis, and that it may serve as an important therapeutic target of HCC.

\section{Acknowledgements}

The authors would like to thank all the members of Key Laboratory of Pathogen Biology and Immunology (Ningxia Medical University, Yinchuan, China) for their assistance. The present study was supported by the Ningxia Natural Science Foundation Program (grant no. NZ14139) and the West China First-Class Discipline Construction Project in Basic Medicine funded by Ningxia Medical University.

\section{References}

1. Eiró N, Altadill A, Juárez LM, Rodríguez M, González LO, Atienza S, Bermúdez S, Fernandez-Garcia B, Fresno-Forcelledo MF, Rodrigo L and Vizoso FJ: Toll-like receptors 3, 4 and 9 in hepatocellular carcinoma: Relationship with clinicopathological characteristics and prognosis. Hepatol Res 44: 769-778, 2014.

2. Shlomai A, de Jong YP and Rice CM: Virus associated malignancies: The role of viral hepatitis in hepatocellular carcinoma. Semin Cancer Biol 26: 78-88, 2014.

3. Vescovo T, Refolo G, Vitagliano G, Fimia GM and Piacentini M: Molecular mechanisms of hepatitis $\mathrm{C}$ virus-induced hepatocellular carcinoma. Clin Microbiol Infect 22: 853-861, 2016.

4. Jack CS, Arbour N, Manusow J, Montgrain V, Blain M, McCrea E, Shapiro A and Antel JP: TLr signaling tailors innate immune responses in human microglia and astrocytes. J Immunol 175: 4320-4330, 2005.

5. Zughaier SM, Zimmer SM, Datta A, Carlson RW and Stephens DS: Differential induction of the toll-like receptor 4-MyD88-dependent and independent signaling pathways by endotoxins. Infect Immun 73: 2940-2950, 2005.

6. Mehmeti M, Allaoui R, Bergenfelz C, Saal LH, Ethier SP, Johansson ME, Jirström K and Leandersson K: Expression of functional toll like receptor 4 in estrogen receptor/progesterone receptor-negative breast cancer. Breast Cancer Res 17: 130, 2015.

7. Takazawa Y, Kiniwa Y, Ogawa E, Uchiyama A, Ashida A, Uhara H, Goto Y and Okuyama R: Toll-like receptor 4 signaling promotes the migration of human melanoma cells. Tohoku J Exp Med 234: 57-65, 2014

8. Semlali A, Reddy Parine N, Arafah M, Mansour L, Azzi A, Al Shahrani O, Al Amri A, Shaik JP, Aljebreen AM, Alharbi $\mathrm{O}$, et al: Expression and polymorphism of toll-like receptor 4 and effect on NF- $\mathrm{BB}$ mediated inflammation in colon cancer patients. PLoS One 11: e0146333, 2016.

9. Luo XZ, He QZ and Wang K: Expression of Toll-like receptor 4 in ovarian serous adenocarcinoma and correlation with clinical stage and pathological grade. Int J Clin Exp Med 8: 14323-14327, 2015.
10. Shui IM, Stark JR, Penney KL, Schumacher FR, Epstein MM, Pitt MJ, Stampfer MJ, Tamimi RM, Lindstrom S, Sesso HD, et al: Genetic variation in the toll-like receptor 4 and prostate cancer incidence and mortality. Prostate 72: 209-216, 2012.

11. Huang HY, Zhang ZJ, Cao CB, Wang N, Liu FF, Peng JQ, Ren XJ and Qian J: The TLR4/NF- $\kappa B$ signaling pathway mediates the growth of colon cancer. Eur Rev Med Pharmacol Sci 18: 3834-3843, 2014.

12. Chen X, Zhao F, Zhang H, Zhu Y, Wu K and Tan G: Significance of TLR4-MyD88 expression in breast cancer. Int J Clin Exp Pathol 8: 7034-7039, 2015.

13. Wang L, Zhu R, Huang Z, Li H and Zhu H: Lipopolysaccharide-induced toll-like receptor 4 signaling in cancer cells promotes cell survival and proliferation in hepatocellular carcinoma. Dig Dis Sci 58: 2223-2236, 2013.

14. Liu WT, Jing YY, Yu GF, Han ZP, Yu DD, Fan QM, Ye F, Li R, Gao L, Zhao QD, et al: Toll like receptor 4 facilitates invasion and migration as a cancer stem cell marker in hepatocellular carcinoma. Cancer Lett 358: 136-143, 2015.

15. Heinrich EL, Walser TC, Krysan K, Liclican EL, Grant JL, Rodriguez NL and Dubinett SM: The inflammatory tumor microenvironment, epithelial mesenchymal transition and lung carcinogenesis. Cancer Microenviron 5: 5-18, 2012.

16. Grivennikov SI: Inflammation and colorectal cancer: Colitis-associated neoplasia. Semin Immunopathol 35: 229-244, 2013.

17. Kawanishi S, Ohnishi S, Ma N, Hiraku Y, Oikawa S and Murata M: Nitrative and oxidative DNA damage in infection-related carcinogenesis in relation to cancer stem cells. Genes Environ 38: 26, 2017.

18. Rasic I, Radovic S and Aksamija G: Relationship between chronic inflammation and the stage and histopathological size of colorectal carcinoma. Med Arch 70: 104-107, 2016.

19. Langrish CL, Chen Y, Blumenschein WM, Mattson J, Basham B, Sedgwick JD, McClanahan T, Kastelein RA and Cua DJ: IL-23 drives a pathogenic $\mathrm{T}$ cell population that induces autoimmune inflammation. J Exp Med 201: 233-240, 2005.

20. Kolls JK and Lindén A: Interleukin-17 family members and inflammation. Immunity 21: 467-476, 2004.

21. Toussirot É: The IL23/Th17 pathway as a therapeutic target in chronic inflammatory diseases. Inflamm Allergy Drug Targets 11: 159-168, 2012.

22. Kortylewski M, Xin H, Kujawski M, Lee H, Liu Y, Harris T, Drake C, Pardoll D and Yu H: Regulation of the IL-23 and IL-12 balance by Stat 3 signaling in the tumor microenvironment. Cancer Cell 15: 114-123, 2009.

23. Wu D, Wu P, Huang Q, Liu Y, Ye J and Huang J: Interleukin-17: A promoter in colorectal cancer progression. Clin Dev Immunol 2013: 436307, 2013

24. Qin S; Primary Liver Cancer Diagnosis and Treatment Expert Panel of the Chinese Ministry of Health: Guidelines on the diagnosis and treatment of primary liver cancer (2011 edition). Chin Clin Oncol 1: 2304-3865, 2012

25. Chen ZH, Hong YF, Lin J, Li X, Wu DH, Wen JY, Chen J, Ruan DY, Lin Q, Dong M, et al: Validation and ranking of seven staging systems of hepatocellular carcinoma. Oncol Lett 14: 705-714, 2017.

26. Song Y, Zhou M, Cao Y, Qi J, Geng J and Liu X: Expression of GLP-1 receptor and CD26 in human thyroid C-cells: The association of thyroid C-cell tumorigenesis with incretin-based medicine. Oncol Lett 13: 2684-2690, 2017.

27. Livak KJ and Schmittgen TD: Analysis of relative gene expression data using real-time quantitative PCR and the 2(-Delta Delta C(T)) method. Methods 25: 402-408, 2001.

28. Ruifeng G, Yunhe F, Zhengkai W, Ershun Z, Yimeng L, Minjun Y, Xiaojing S, Zhengtao Y and Naisheng Z: Chlorogenic acid attenuates lipopolysaccharide-induced mice mastitis by suppressing TLR4-mediated NF- $\mathrm{BB}$ signaling pathway. Eur J Pharmacol 729: 54-58, 2014.

29. Langowski JL, Zhang X, Wu L, Mattson JD, Chen T, Smith K, Basham B, McClanahan T, Kastelein RA and Oft M: IL-23 promotes tumour incidence and growth. Nature 442: 461-465, 2006.

30. Zhou Y, Wu PW, Yuan XW, Li J and Shi XL: Interleukin-17A inhibits cell autophagy under starvation and promotes cell migration via TAB2/TAB3-p38 mitogen-activated protein kinase pathways in hepatocellular carcinoma. Eur Rev Med Pharmacol Sci 20: 250-263, 2016. 
31. Sakurai T, Kashida H, Watanabe T, Hagiwara S, Mizushima T, Iijima H, Nishida N, Higashitsuji H, Fujita J and Kudo M: Stress response protein cirp links inflammation and tumorigenesis in colitis-associated cancer. Cancer Res 74: 6119-6128, 2014.

32. Wang H, Liu J, Hu X, Liu S and He B: Prognostic and therapeutic values of tumor necrosis factor-alpha in hepatocellular carcinoma. Med Sci Monit 22: 3694-3704, 2016.

33. Grivennikov SI, Wang K, Mucida D, Stewart CA, Schnabl B, Jauch D, Taniguchi K, Yu GY, Osterreicher CH, Hung KE, et al: Adenoma-linked barrier defects and microbial products drive IL-23/IL-17-mediated tumour growth. Nature 491: 254-258, 2012.

34. Blauvelt A, Lebwohl MG and Bissonnette R: IL-23/IL-17A dysfunction phenotypes inform possible clinical effects from anti-IL-17A therapies. J Invest Dermatol 135: 1946-1953, 2015.

35. González-Reyes S, Marín L, González L, González LO, del Casar JM, Lamelas ML, González-Quintana JM and Vizoso FJ: Study of TLR3, TLR4 and TLR9 in breast carcinomas and their association with metastasis. BMC Cancer 10: 665, 2010.
36. Kulig P, Burkhard S, Mikita-Geoffroy J, Croxford AL, Hövelmeyer N, Gyülvészi G, Gorzelanny C, Waisman A, Borsig L and Becher B: IL17A-mediated endothelial breach promotes metastasis formation. Cancer Immunol Res 4: 26-32, 2016.

37. Teng MW, Bowman EP, McElwee JJ, Smyth MJ, Casanova JL, Cooper AM and Cua DJ: IL-12 and IL-23 cytokines: From discovery to targeted therapies for immune-mediated inflammatory diseases. Nat Med 21: 719-729, 2015.

38. Brentano F, Ospelt C, Stanczyk J, Gay RE, Gay S and Kyburz D: Abundant expression of the interleukin (IL)23 subunit p19, but low levels of bioactive IL23 in the rheumatoid synovium: Differential expression and Toll-like receptor-(TLR) dependent regulation of the IL23 subunits, p19 and p40, in rheumatoid arthritis. Ann Rheum Dis 68: 143-150, 2009.

c) (i) (9) This work is licensed under a Creative Commons CY NG No Attribution-NonCommercial-NoDerivatives 4.0 International (CC BY-NC-ND 4.0) License. 